\title{
EEN VERHANDELING OVER HET ONTSTAAN VAN HET MENANGKABAUSCHE RIJK EN ZIJN ADAT. \\ DOOR
}

Dr. F. W. STAPEL.

De opperkoopman Coenraad Frederik Hofman, gezaghebber over Sumatra's Westkust en tevens stadhouder vanwege den „keyser” van Menangkabau over de strandlanden, stelde in den loop van 1715 een verhandeling samen over het ontstaan van het Menangkabausche rijk en de daar heerschende zeden en gewoonten, o.a. het matriarchaat. Hij had daartoe aanleiding gevonden in het feit, dat de Hooge Regeering te Batavia hem haar ontevredenheid had betuigd over de benoeming van een nieuwen pongloe ${ }^{1}$ ) in de plats van een overleden raadsheer. Als vertegenwoordiger der Compagnie had Hofman aan die benoeming zijn zegel moeten hechten, en de regeering meende, dat hij daarbij niet de noodige ernst had betracht, zoodat niet de meest rechthebbende zou zijn benoemd. Daartegen kwam Hofman met kracht op en hij hoopte met zijn verhandeling de regeering te overtuigen , geen ander insigt [te] hebben geharl als de billikheyt". Hij zond daartoe het document, dat hij had samengesteld uit verschillende ,Maleytse gedenckschriften” en mondelinge overleveringen, met een begeleidend schrijven van 31 Januari 1716 naar Batavia: „Ter speculatie van Uw HoogEd. heb ik, op hoope van welduydinge, de vryheyt genomen hiernevens te voegen myne particuliere aentekeninge van den eersten oorspronk deser gemengde regeringe, en door welcke gevallen die van tijt tot tijd is veranderd geworden".

Het komt slechts sporadisch voor, dat ambtenaren der Compagnie belangstelling toonen voor de zeden en gewoonten der inheemschen, in wier gebied zij werkzaam zijn. Mannen als Cornelis Speelman, die een van grondige studie getuigende Notitie opstelde over de geschiedenis en adat der volkeren van Zuid-Celebes, en een kleine tien jaar later even degelijke kennis toonde van de inwendige ver-

1) Panghoeloe, dat aan de Westkust beteekende regent of raadsheer. 
houdingen in Mataram en de onderlinge relaties der Javaansche grooten, behooren tot de uitzonderingen. Daarom laten wij hier de verhandeling van Hofman volgen, na eerst iets te hebben medegedeeld over de loopbaan van den auteur.

Hofman was een Duitscher; zijn geboorteplaats wordt in 's Compagnies papieren afwisselend gespeld Essingen, Assenen, Assenhem en Hassenheym. Hij moet omstreeks 1666 zijn geboren en kwam in 1686 met het schip Oosterlandt op Batavia an als adelborst, op een gage van f 10 per maand. Zijn eerste plaatsing was op Padang. waar men hem, wegens zijn bekwaamheid in het schrijven en rekenen, ,,aen de pen” plaatste. In 1693 benoemde gezaghebber Abraham Boudens hem tot assistent op f 24 , maar de regeering vond deze benoeming te eigenmachtig en bovendien het salaris te hoog; zij stelde Hofman terug tot adelborst. Dit was echter slechts een tijdelijke maatregel, want zijzelf benoemde hem in 1695 tot assistent op Ambon, op f 20. Sedert diende Hofman achtereenvolgens op Ambon. Ternate en Batavia, en klom geleidelijk op tot onderkoopman en koopman. Als eerste administrateur van het ijzermagazijn der Compagnic op Batavia (1708) trok hij de aandacht van zijn superieuren en hij maakte daar een zeer gunstigen indruk. Daarom benoende de regeering hem 25 April 1710 tot gezaghebber der Westkust, met rang van opperkoopman. Zoo kwam Hofman dus in de hoogste waardigheid terug op dezelfde plaats, waar hij 24 jaar te voren als adelborst zijn looplaan was begonnen. Een mooi resultaat, maar dat zou worden gevolgd door een diepen val!

Bij resolutie van 11 Mei 1717 ontbood de regeering Hofman en vier zijner voornaamste ondergeschikten naar Batavia. Zij was op het spoor gekomen van .,het dryven van een gansch uytsporigen perticulieren hanclel en het misbruycken van 's Compagnies gelt tot deselve”. Door onderling krakeel was de zaak uitgelekt, en naar den voorloopigen indruk scheen daarin .,den gesaghebber Hofman, tegen alle verwagtinge ende voorgaende opinie wegens sijn persoon en gedrag, wel het grootste deel te hebben". Dezelfde resolutie bepaalde, dat de oud-gezaghebber Abraham Schepmoes als commissaris naar de Westkust zou gaan om ter plaatse een onderzoek in te stellen, terwijl Abraham Patras hem zou vergezellen om de gezaghebbersplaats te vervullen.

Den 9den December kwam Schepmoes op Batavia terug; zijn onderzoek had uitgewezen, dat inderdaad ergerlijk was geknoeid. In 's Compagnies kas constateerde hij een tekort van 43975 rijks- 
daalders. Onmiddellijk liet de regeering de beschuldigden, die tot dusver op Batavia vrij hadden rondgeloopen, in de boeien (gevangenis) zetten, en verwees de zaak naar den Raad van Justitie.

Ofschoon de beschuldigden allen bekenden, diende de fiskaal tegen Hofman een eisch ad torturam in, die hem evenwel bij vonnis van 5 October 1718 werd ontzegd, met opdracht tot verder procedeeren. Eerst den 9den September 1719 deed de Raad van Justitie uitspraak: Hofman werd gedeporteerd van ambt, qualiteit en gage; verklaard te zijn , infaem en inhabiel on de Ed. Comp ${ }^{\text {ie }}$ na desen in eenig employ van eere te dienen"; hij en zijn medebeklaagden werden gezamenlijk en ieder in solidum aansprakelijk gesteld voor de restitutie der 43975 rijksdaalders, en moesten in het publiek gestrengelijk worden gegeeseld en in de ketting geklonken, om vervolgens de Compagnie als kettingganger te dienen zonder loon. Voor Hofman werd deze dwangarbeid bepaald op 15 jaar (hij was toen al over (le 50 jaar oud!).

Van dit vonnis vroeg Hofman revisie aan, op grond dat in de sententie een ,erreur” zou schuilen, ,en hetselve corrigerende speciaal het publicq aan te doene schandaal op 't schavot, met den aankleven van dien, soude werden ontsegt". Bij vonnis van 14 Mei 1720 verklaarde de Raad van Justitie het verzoek om revisie niet ontvankelijk en het vonnis van 9 September 1719 werd een jaar later. 7 September 1720, geëxecuteerd. Ten slotte wees de Hooge Regeering bij resolutie van 11 October 1720 de Kaap de Goede Hoop aan als plaats, waar de delinquent zijn 15 jaar dwangarbeid moest afdoen.

\section{OPCOMST DER PADANGNEESEN EN DERSELVER REGERINGE $\left.{ }^{1}\right)$.}

Padang, soo genaent na 't groote, vlakke veld binnen een ringmuur van hooge bergen opgeslooten ${ }^{2}$ ), is, sooverre de Maleytse gedenckschriften heugen, eerst bewoont geweest van vissertjes, zoutkookers en handelaers, onder een hooft, die den titul voerde van

1) Uit de Orergecomen bricien 1717. 12de boeck, afdeeling Sumatra's Westcust, folio 17 e.v.

2) Maleisch padang beteekent vlakte of plein. Men vergelijke bij het volgende vooral Westenenk, De Minang Kabansche Nagari en Kielstra, Onze kennis ian Sumatra's Westkust omstreeks de helft der achtticnde eeua, in Bijdragen Koninklijk Instituut 1887, blz. 499 en volgende. 
mochodon ${ }^{1}$ ), en een tweede, van de priesterlycke ordre, gekomen van Passey, leggende benoorden Aetchin, met den titul van sangoena (luradja ${ }^{2}$ ). Dese, door de bergvolckeren beoorloogt werdende wegens sekere moord, door een harer onderdanen, genaemt Campang-China, begaen aen een bergman, genaemt Serpajaya van Tzinanhi, die om zout te koken afgecomen ware, sloegen in den beginne de bergvolckeren met een verlies van 30 mannen aff; dog daerna bevreest voor een sterckere magt, sonden sy een inboorling van Sancara, genaemt Malimganja, daer ten handel gecomen, na de vergramde bergvolckeren om 't verschil te bemiddelen. onder presentatie van vergoedinge voor de gelediene schaden, en vercregen daerop ook dat den dato bhandara Pagagar van Boukit Pantang met veele andere berggroten omlaeg op Padang afquamen. Maer dewyle den eysch 1n goud, welcken voor de vergoedinge deden, veel te groot ware om door die arme vissertjes voldaen te werden, lieten haer de bergvolckeren vergenoegen met de aenbiedinge van de helfte van 't $\mathrm{Pa}$ langse land in plaetse, en namen ook al ten eersten 't besit daervan, nadat de Padangneesen den duursten eed van trouwe, onder den ingesetenen bekend, aen haer afgelegt hadden, welcken bestaet in 't slagten van een onschuldige mans-slaev en 't verbranden van desselfs lighame tot assche, die vervolgens in de zee weggesmeten werd, en 't sweeren by haren Godt, dat wanneer ontrouw wierden, (leselfde straff over haer en de hare mogte komen; sulx ${ }^{3}$ ) van die tijd af de bergvolckeren evenveel magt met de strandvolckeren op Padang vercregen hebbende, ook gelyke deel in de regeringe namen, deselve componeerende uyt agt persoonen, als vier uyt de strandvolckeren en vier uyt de bergvolckeren, onder de benaminge van Sapamingirnja, betekenende strandvolckeren, en Sadareenja, bergvolckeren, waervan de eerste van dese gemengde regering sijn geweest, van de strandvolckeren:

Een van 't geslagte Beeli-messian ${ }^{4}$ ), soo genaemt na de titul van de huysvader ofte opperste van eenige huysgesinnen, welcke, met verlatinge van hun geboorteplaetse Priangan ${ }^{5}$ ), om costwinninge haer

1) De titel machoedoem schijnt van Arabischen oorsprong te zijn. Zie o.a. De Minang Kahausche Nagari, blz. 30, noot 4.

?) ?

3) Zoodat.

4) KinlstrA, 1.c. blz. 526, noemt het Kotta-Tengahsche geslacht Baleimasiang.

5) Zie Westenexk, Opstellen oier Minangkaban II, Tijdschrift van het Bataviaasch Genootschap, I.VII, blz. 241 e.v., vooral 244. Ook diens Dc Minang Kabausche Nagari, blz. 2. 
eerst binnen 't landschap Agam en vervolgens op Tanamera terneder geset hebben, van waer eenige op Padang sijn overgecomen.

Een van 't geslagte Tanjong ${ }^{\mathbf{1}}$ ), alsvooren gesprooten uyt Priangan, welcke haer op Passaman hebben terneder geset, waervan in 't vervolg om costwinninge mede eenige op Padang sijn aengecomen.

Een van 't geslagte Maleyo, dies naeste afcomst van Indrapoera werd gerekent, ondat de ware geboorteplaetse 't geheugen ontschooten is.

Een van 't geslagt Mandeiling; heeft mede niet anders overgehouden als de bloote naem.

Van de bergvolckeren:

Dato Maradja-besaer, Orangcaya-besaer, Radja Phalawan en Dato Radja Pagaga, alle afkomstig, na der meeste geroelen, van Tzinanhi, de negory daer den vermoorden onderdaen Serpajaya thuys hoorde. (log van verscheyde familiën.

In desen staet een tijd lange gecontinueert hebbende, sonder andere mogentheyt boven haer te erkennen, gelijk te dier tijd ook 't geheele land nodig is verdeelt geweest byna in sooveele gemeentens, onder haer eygene hoofden, als 'er negoryen waren, totdat zeker inboorling ${ }^{2}$ ) van de negorye Priangan in th gebergte van allen omliggenden volckeren vrywillig gehoorsaemt wierde, uyt een bygeloovig gevoelen, dat met godlyke eygenschappen begaeft ware, gelijck ook nog heden gelooft werd, die, om sijn naem en ontsag te vermeerderen, deselve vereenigde en bragte tot één lichaem onder een rijksvergaderinge der voornaemste hoovden uyt de magtigste negoryen, om gesamentlijck nevens hem en sijn ouder broeder Katommogongon ${ }^{3}$ ) als voorsittende hoofden des reyks saken met volle magt te bestieren, tot welcke byeenkomste hy verkoos de plaetse van Maningcabou, een landschapje in 't midden van dat vereenigt lighaam gelegen, waervan 't ook de naem van 't Minangcabouse rijk vercreeg; alsook wyders voor de veiligheyt en geduursaemheyt van dat rijk, on de heersugtige voornemens tot usurpatie te konnen breidelen, den rijxraed verdeelde in twee hooft- ofte coninglyke stammen, met namen Tziniago en

1) Kielstra schrijft Tongsong.

2) Papatih van Sabatang. Zie Westexexk, Opstellen oi'er Minangkabau, I, Tijdschrift van het Bataviaasch Genootschap, LV, blz. 238 e.v. en II, blz. 246, met de daar genoemde literatuur. Ook diens Minang Kabausche Nagari. blz. 28 e.v.

3) Zie voor Katômanggoenan ibidem. 
Cotta-duplian ${ }^{1}$ ), yder stam, om even magtig te sijn, gelyke magt van volck en landschapen toevoegende, met last dese ordre in de successie te agtervolgen van altijd in der afgaende plaetsen persoonen van deselfde stamme te stellen.

De eerstgenoemde stam Tziniago, waervan hy sigselve 't voorsittend hooft noemde, formeerde hy uyt de volgende volckeren van ${ }^{2}$ ) : Lima-Caon (Lima Kaoem), Douablas-Cottas, Bangsar, Payacomboe (Pajo-Koemboeh), Tahy (Taeh). Hinelangan (Si Malanggang), Taram, Batoe-Balang. Sitoejoe, Bantar-dalam, Benah-Ayer-Terpit (Ajer Tabi?), Sompoe (Soempoe), Malala, Solok, Goegoe (Goegoea), Cotta-Anoe (Kota Anau), Tzinanhi, Tanjong-Binko, TalagaPadlang. Paya, Belimping. Songi-Lassi, Boekit-Moentzjong. Caon (Gaoeng), Paniahalang (Panjakalang), Seroekan, Songi-Cabayang, Kontchir. Songi-Tzjerroeay, Katiala, Cadjang-Rassan, Camoe-Kitchil en Camoe-Gadang.

De tweede hooftstamme. onder sijn broeder Katommogongon, uyt de volgende volckeren van: Soeroeassa, Padang-Ganting, Songi-Trap (Soengai Taro), Agam, Batipoe (Bati-poeah), Priangan (Pariangan ${ }^{3}$ ). Padang-Panjang. Renan, Manhawat, Goenoeng-Panyawan. Soemanik, Koerey-Benoe. Ampoe, Tanjong-Belit, Zoeli-Ayer (Koeti Ajer?), Saleyo (Salajo), Cotta-Baroe, Kenari (Kinari), MoaraPanas, Tallang (Talang), Tzioepa (Tjoepak), Gantong-Tzeri, Sancara (Singkara), Sening-Bahat, Seloenkan (Siloengkang), Padang Siboessoe, Songi-Pagoe en Corintsche (Korintji).

Door de gemaekte rijxconstitutie is de hoogste magt aen de voornaemste hoofden dier twee hooftstammen ook verbleven, soodat den Sultan, wiens af-. aen- en opkomst tot den Minangcabousen throon. nadat 't rijk soodanig is bestelt geweest. met sulcke belaghelyke omstandigheden verzelt is, dat niet sekers daervan kan werden geseyt, alleenlijck 't hooft van de rijxvergaderinge representeert, en verders geheellijck van der rijxgrooten goedagten afhangt.

Wyders veranderde gedagte Berpatty Sabatan ook veel oude gewoontens, sommige geheellijck vernietigende en andere wetten weder in plaetse stellende.

1) Zie voor de Bodi-Tjaniago en de Koto-Piliang Dc Minang Kabauschc Vagari, blz. 40 e.v. Kiel.stra schrijft, blz. 526. Tjieniago.

2) De tusschen haakjes geplaatste namen zịjn er door mij ter verduidelịking biigevoegd.

3) Zie hiervóór noot 5 op blz. 462. 
t Regt der erfflatinge en opvolginge in amten en staten ontnam hy d'eygen kinders, om reden, sooals de Maleytse gedenkschriften melden, sijn eygen soon geweygert heeft op bevel van hem sig in doodsgevaer te begeven en sijn susters zoon integendeel 't selve gehoorsaemelijck heeft opgevolgt, statuerende ten opsigte der erflatinge, dat de susterskinderen met d'eygen kinderen gelykelijck sullen erven en deelen; en noopende de successie in amten en staten, dat by gebrek van broeders van eenen bedde 't selve regt sal overgaen op de susterskinderen van manlycken oire; en dese mede ontbrekende op de naeste neven van der susterssyde, tot den laetsten graed toe, mits de outste de jongste geprefereert werden en 't mannen sijn van een goede levensleydinge en bequaemheyt, waerop men 't bestier der gemene saken sal konnen vertrouwen. Dog dese alle ontbrekende dan daertoe te verheffen een van een andere familie uyt deselffle gemeente en by 't volck 't meeste bemint.

Tegens de moordenaers en doodslagers voerde hy in de wet der wrake, welcke aen de broeders, susters-sonen en neven van de susterssyde, volle magt gaf de moord, begaen aen hun naeste magen, te mogen wreken, òfte aen de moordenaer selfs, met hem van 't leven te berooven, òfte aen syne have, met die alle na sig te nemen, òfte. bygeval de moordenaer sig en syne have tesoek maekte, aen desselfs broeders, susters-zoonen en neven van de susters-syde, tot den laetsten graed toe.

Welcke wet hy mede betrekkelijck maekte op rle schuldenaers, om in plaetse van den gebrekigen debiteur dessels broeders ofte naeste magen van de susters-syde te mogen aenspreken tot voldoeninge.

En in 't algemeen tegens de schade, van buyten ymand aengedaen werdende, 't sy van nabuurige ingesetenen ofte van vreemde, vernieuwde hy 't regt van verhael, door middelen, daertoe noodig, ook sonder consent der overigheyt, willende dat een yder toegelaten sy 't hem aengedane ongelijck selfs te wreken.

Maer d'oude wet van salam-ayer. suyveringe welcke door 't water geschiedde, by wyse dat de twistende partye, die door gebrek van getuygenis niet kon gescheiden ${ }^{1}$ ) werden, in 't water moste springen, waervan den dryvenden, ofte dien in 't water de neus ontsprong. voor schuldig wierde verclaert, veranderde hy en stelde in plaetse den eed van suyveringe, welcke geschiede door 't leggen van de hand op een steen en aenroepinge van syn Godt, dat indien schuldig sy, door steenen mogte verplettert werden.

1) Er staat geschieden.

D1. 92. 
Dese wetten en meer andere insettingen, voor 't nodig onderhout door een verdeelinge der winstsoekinge over 't geheele land, om de schaersheyt van levensmiddelen te verhoeden, by allen volckeren van dat vereenigde lichaem als sooveele godsspraken gehoorsaemlijck aengenomen sijnde, hebben de strandvolckeren, van Indrapoera af tot Passaman toe, deselve mede aengenomen en van dien tijd af haer ook gerekend onderhorige van gemelte rijk, te weten:

Die van Tzinanhi, namelijk de familiën van Samague, Mandelika, Jamba en Pangnjali, onderhoorige van de hooftstamme Tsjiniago, waervan gemelte negory een licl is, en die van de familiën ofte geslagten Belimessian en Tanjong, onderhoorige van de hooftstamme Cotta-dupilian, omdat de negory Priangan, waeruyt hun eerste afcomst rekenen, een lic van gemelte hooftstamme is, met welcke laetste die van de geslagten Maleyo en Mandeiling (dier regte afkomst, gelijck hiervooren staet vermeld, onseker is) haer hebben gevoegt en alsoo haerselven vrijwillig aen dat rijk onderdanig gemaekt, dog sonder oyt eenige schattingen daeraen te betalen, alsoo den wetgever, meergedagte Berpatty Sabatan, om sigh te eerder een grooten aenhang te vercrygen, ook niet gewilt heeft dat van ymand door 't geheele land eenige schattingen aen 't rijk souden werden betaelt: dan, na verloop van tyden door de onderlinge tweedragt der regenten over de hoogere magt, welcke de meeste strandvolckeren verdeelt hielde, van d'Aetchinders overheert sijnde geworden, wierden sy daaraen oock tributair gemaekt en yder negery langs 't geheele strand tot bewijs van onderdanigheyt jaerlijx geschat op 20 rijxdaelders ten behoeven van de Aatchinse croone, 't welcke duurden ontrent 18 jaren, totdat sy in den jare 1666 door 's Compagnies magt van 't Aatchinse juk weder verlost en dese strandlanden by accoord d'E. Comp ie ingeruymt wierden, om deselve in den name van Maningcaboe, onder den titul van stadhouder, met volle magt te bestieren.

$\mathrm{Na}$ welcke inruyminge den Paadangnees, genoemt Orangcaya Kitchil, die on syne goede diensten, by die gelegentheyt d'E. Comp ${ }^{\text {ie }}$ gedaen, tot panglima-radja verheven wierde, met bewilliginge van den Nederlandsen raet de Padangse regeringe, bestaende volgens haer eerste instellinge nog uyt 8 personen, met gelyke magt ontrent het gebied, veranderde, twee der oude regenten, namelijck de persoonen van Orangcaya Basaer en Radja Palawan, over dat de syde der Aatchinders gehouden hadden, met alle hare nacomelingen ten eeuwigen dage toe daeruyt verbande, en 't overige getal ver- 
meerderde tot 12 persoonen, gevende aen den voorsitter ofte eerste pongloe de character van bhandara.

By welcke nieuwe constitutie de regeringe ten opsigte van 't opperbevel, dat den panglima-radja boven alle andere inlandse regenten gegeven wierd, en van 't meerder getal der regenten, ook is gebleven; dog van de ordre der successie is meermalen afgeweken geworden. en t'effens in de regeringe gesien vader, broeder en zoon, namelijck den Orangcaya Kitchil in qualité van panglima-radja, Mage Sanporna, desselfs ouder broeder, in qualité van dato-bhandara, en de eygen soon van de laestgenoemde in qualité van pongloe, met den titul van radja-darata, present panglima-radja, alsook ontrent eenige andere familiën, gelijck de lijste der persoonen, welcke by dese nieuwe constitutie de regeringe uytmaekten, en derselver successeurs, soo als die den anderen successive tot heden opgevolgt sijn, aentoont, namelijck :

Den panglima-radja, genaemt Orangcaya Kitchil, uyt 't geslagte der Beli-messian, heeft tot opvolger gehad desselfs sone, genaemt Radja Alam, welcken om sijn wrevelmoed afgeset sijnde, wierde de linie voorbygegaen en tot panglima-radja vercooren Maradja Inda, uyt 't geslagte Tanjong; $\mathrm{en}$ in desselfs plaetse, overmits vóór 't aenveerden van 't bestier tot Batavia vermoort wiert, gestelt desselfs broeder, Moara Laout, welcken over ontrouwe na Banda verbannen sijnde, is gevolgt den presenten panglima-radja, Darat, sijncle van de vaderssyde uyt 't geslagte Beli-messian, en van de moedersyde uyt het geslagte Samague. ${ }^{1}$ )

Den dato-bandara, genaemt Mage Samporna, uyt 't geslagte Belimessian, sijnde de ouder broeder van den panglima-radja Orangcaya Kitchil, is gevolgt desselfs broeder, mede genaemt Orangcaya Kitchil; dese desselfs broeder-zoon, genaemt Radja Daraet, en mits de optredinge van den laetsten tot panglima-radja, den presenten datobandara uyt 't geslagte Samague.

Den pongloe Datoe Maradja Basaer uyt 't geslagte Samague is gevolgt desselfs susters sone, onder deselve titel van Datoe Maradja Bezaer; en desen, vermits syne optredinge tot datoe-bandara, desselfs soon, den presenten pongloe, Radja Inhan.

1) Kielstra, blz. 522, schrịift Simagé. 
Den pongloe Radja Goenong Pandang uyt 't geslagte Beli-messian is gevolgt Radja Adil, desselfs susters-soone; en clese weder den presenten pongloe. Radja Alam, de susters-sone van gedagte Radja Adil.

Den pongloe Radija du Paclang uyt 't geslagte Jamba ${ }^{1}$ ) continueert nog.

Den pongloe Maradja Nanda uyt 't geslagte Tanjong is gevolgt desselfs susters-zone Jibon: dese desselfs broeder, radja Inda Phalawan; dese weder radja Boedjang, de zoon van den pongloe Maradja Nanda, en na desen de susters-soon van radja Inda Phalawan, genaemt Maradja Indo. Dese, over ontrouwe uyt de regeringe geset, is gevolgt den presenten pongloe Soutan Ibrahim, uyt 't geslagte Beli-messian. sijnde de jongste broeder van den pongloe radja Alam.

Den pongloe Soetan Moelano uyt 't geslagte Beli-messian is gevolgt radja Nangcaya, desselfs susters-sone; en dese den presenten pongloe radja Indraboemi, susters-sone van den laestgenoemden radja Nangcaya.

Den pongloe Paducca Maget uyt 't geslagte Mandeiling is gevolgt desselfs susters-soon Berbangsa Duradja; desen, na Banda versonden sijnde, is desselfs familie voorbygegaen en tot dat ampt verkooren den persoon van radja Marach, uyt 't geslagte Maleyo; dan, desen sonder broeders ofte wettige colateralen na te laten overleden sijnde. is gevolgt den presenten pongloe radja nang Poetti ${ }^{2}$ ), uyt 't geslagte Samague, sijnde de zoon van den overleden pongloe, radja Adil, en neev van den presenten dato bhandlara, datoe Maradja Besaer.

Den pongloe Orangcaya Soeradja uyt 't geslagte Samague is opgevolgt desselfs susters- soone Siribijdja Indra; desen radja Darat. de susters-sone van gedagte Siribijdja Indra, en na desen weder de jongste broeder van gemelte radja Darat, onder deselfde tytel, die ook nog continueert.

Den pongloe Datoe Gapon uyt 't geslagte Maleyo is gevolgt Maradja Lela, desselfs susters-zoon: en desen weder den presenten

1) Ibidem, blz. 523, Djamba.

־) Bij Kielstr.ı, blz. 525. Anachoda Poetih. 
pongloe Datoe Gapon. sijncle de susters-soon van gedagte Maradja Lela.

Den pongloe Radja Sittia Goera uyt 't geslagte Maleyo is gevolgt Tommogon, desselfs broeder: desen radja Sittia Inda, de susterssone van gedagte Tommogon, en na desen den presenten pongloe Abdul Carim, sijnde de susters-sone van radja Sittia-Inda.

Den pongloe Radja Pagagar uyt 't geslagte Mandelika is gevolgt radja Seleman uyt 't geslagte Pangnialy; en op desen den presenten pongloe Soetan Ame, desselfs susters sone.

Den pongloe Radja Dilheer ${ }^{1}$ ) uyt 't geslagte Mandelika is gevolgt desselfs neev, den presenten pongloe Radja Maningtang.

De andere insettingen van den stigter der Minangcaboesen rijx. Berpatti Sabatan, sijn t'sedert door de veranderinge van tyden, dat 't Mhometaense geloof onder den meesten ingesetenen is aengenomen geworden, ook langsamerhand weder in onbruyk geraekt.

Tot d'erffenis d'eyge kinderen weder gewettigt; dan, alleen met die verpligtinge, dat sy een smal gedeelte van de erffenis na eygen believen aen de susters-kinderen tot een gedagtenis uytkeeren.

De wet, om sigselven te mogen wreeken, vernietigt, en dese magt aen de overheyt gegeven, welcke heden 's daegs alleenlijck de doodslagen, van mindere-stands persoonen begaen aen lieden van agtinge en vermogen, met de doodt straft, maar ontrent gelycke-stands persoonen ofte aen een van geringe conditie gecommitteert werdende. kan den doodslager sig vrycoopen met 400 rijxdaelders. En van den doodslag aen een slaef begaen met 20 rijxdaelders, welcke somma òfte door den doodslager selven, òfte door syne naeste magen moet vergoet werden volgens de wet, tegens de schuldenaers gestatueert. welcke nog heden in haer volle vigueur blijft.

't Regt van verhael, de slimste kancker') van de ruste op dese cust, heeft nogh meest plaetse, omdat de overheyt van den belediger uyt winstsugt weygerig blijft regt te doen, en de overheyt van de beledigde òfte niet magtig is, ofte niet genegen. om de schade, van de nabuuren sijn eygen onderdanen aengedaen, met denselven sig in een oorlog in te wickelen, soodat den beledigden onderdaen, de

1) Radja Ilir.

2) Er staat krancker, wat goed kàn zịn in de beteekenis van krenker. 
schade willende wreken, sulx door verhael moet doen; en alsoo die wrake meest altijd de onschuldige treft, verwekt die tot weerwraek, welcke dan egter gemenelijck door een oorlog moet werden geijndigt. Dog onder 't gebiet der E. Comp' ${ }^{\text {ie }}$ houd die wyse van handelinge op door vreese van straffen, overmits den beledigden, in cas 't regt hem geweygert werd, sijn recours tot d'E. Comp ${ }^{i *}$ behoud.

De wet der suyveringe do: $r$ 't water, door den stigter van 't Minangcaboese rijk, Berpatti Sabatan, afgeschaft, is sedert lange ook weder in gebruyk gebragt, en heeft te meer kragt op de gemoederen der ingesetenen, omdat se geagt werd van God selfs ingestelt en onfeylbaer te sijn, volgens de exempelen, welcke veele daervan weten te verhalen, dat 't wel meermalen gebeurt ware dat persoonen van een hartvogtigen aert en stout, dese beproevinge niet geagt hebbende. de goddelycke kragt in 't water niet hadden kennen tegenstaen, maer of dryvende waren gebleven. ófte, soo al met den onschuldigen wegsoncken ${ }^{1}$ ). (lan egter onder 't water versmoort ofte door een hey ${ }^{2}$ ) ofte caeyman tot vermeerderinge harer straffe weggerukt waren geworden. Dan, dese beproevinge werd niet als in seer twyfelagtige saken partyen opgelegt.

Onder stont: Accordeert, getekent: C. F. Hofman.

1) Er staat wegschoncken.

2) Haai. 